\title{
Solidification behaviour of Ni-base superalloy CMSX-6
}

\author{
D. MA, M. MEYER TER VEHN, P. BUSSE* and P.R. SAHM \\ Giesserei-Institut, RWTH Aachen, Intzestr. 5, 5100 Aachen, Germany \\ * ACCESS e.V., Intzestr. 5, 5100 Aachen, Germany
}

\begin{abstract}
The solidification behaviour of the single crystal superalloy CMSX- 6 has been investigated using directional solidification technique. The longitudinal sections of the quenched samples were taken to identify the solidification structure. The experimentally determined solidification diagram gives the relationship between solidification structure and process parameters. The analysis of the transverse sections yields the solidification sequence and the solid fraction against the temperature decrease. The dendrite spacing was described as a function of solidification parameters.
\end{abstract}

\section{INTRODUCTION}

Single crystal superalloys have been identified as an attractive approach for increasing allowable gas turbine blade temperature. Among the requirements for a successful application of cast single crystal airfoils is the fundamental understanding of the solidification behaviour of the used superalloys.

CMSX-6 is a low density single crystal superalloy, developed by Cannon-Muskegon in conjunction with MTU (1). The chemical composition is given in Table 1 . This alloy is nearly free of $C$ and the grain boundary stabilising elements $\mathrm{Hf}$ and $\mathrm{Zr}$. This leads to an increased melting temperature and an improved high temperature creep rupture strength. Al+Ti are at a high level to ensure the low density $\left(7.98 \mathrm{~kg} / \mathrm{dm}^{3}\right)$ is achieved. In this research a series of directional solidification experiments was performed in order to provide the essential information on the solidification behaviour of CMSX-6.

\section{EXPERIMENTS}

The experiments were performed in a modified Bridgman type of furnace using liquid metal as a coolant. Cylindrical single crystal samples in dense alumina tubes, with [100] crystal orientation in longitudinal direction, were inserted into the heated furnace. The samples were remolten to a point just above their base, which served as a seed. By withdrawing the furnace with controlled rates towards the top the directional solidification was started. The solidification velocity $\mathrm{v}$ was varied over a wide range in order to cover all possible solidification morphologies. The corresponding temperature gradient $G$ was determined by recording the temperature vs. time curves of a thermocouple moving with the samples or directly by using two thermocouples inside of the sample in a short distance of each other. After quenching the single crystalline solidified samples were analysed by common metallographic means.

\section{RESULTS AND DISCUSSION}

The longitudinal sections of the quenched samples were taken to identify the solidification structure. Figure 1 shows the dependence of the growth morphology on the process parameters $G$ and $v$. Lines 
corresponding to constant G/v-ratios define regions within which the interface morphology is planar, cellular, columnar-dendritic or equiaxed-dendritic.

Plane front solidification can be obtained if the G/v-ratio is higher than a critical value of about 150 $\mathrm{Kmin} / \mathrm{mm}^{2}$. With increasing velocity the solidification interface becomes unstable and changes to cellular structure. Crystals having cellular and plane front cast structure exhibit substantially increased ductility and fatigue properties as well as higher incipient melting point (2). However, there has been no significant commercial interest in plane and cellular front superalloys because of the expensive processing costs. Dendritic microstructures were obtained for most of the processing conditions used in the present study. For CMSX-6 it seems to be possible to produce single crystal castings with very fine and homogeneous dendritic microstructure, resulting in improved mechanical properties. Only at extreme high velocities, the directional solidification breaks down and the structure becomes equiaxed dendritic. The critical conditions for the morphology transitions can be taken from the solidification diagram in Fig. 1.

The transverse sections of a dendritically solidified sample were taken at known distances from the dendrite tip, corresponding to liquid temperature $T_{1}$, to carry out metallographic studies. In Fig. 2 the specific area of solidified crystal in the transverse sections as an appropriate approximation for the volume fraction of solid $f_{S}$ is plotted against the temperature decrease $\left(T_{1}-T\right)$. The metallographic analysis suggests that the solidification process of the alloy CMSX-6 starts with the crystallisation of the $\gamma$-phase, and is completed by the eutectic reaction $\mathrm{L} \rightarrow \gamma+\gamma^{\prime}$. Due to the very low concentration of carbon no carbides were observed.

Comparing the evolution of $f_{S}$ with the corresponding micrographs in Fig. 2, the solidification process can be better understood. Behind the dendrite tip there is a zone where the dendrite arms can grow freely, resulting in a quick increase of the solid fraction $\mathrm{f}_{\mathrm{S}}$. After the interfering of the dendrite arms with those of neighbouring dendrites, the solidification in the mushy zone is characterised by a coarsening process of the dendrite arms. Due to the interdendritic segregation, leading to the reduction of the liquidus temperature, and the release of the latent heat, the increase of the solid fraction $f_{S}$ was slowed down until the eutectic solidification occurs.

CMSX-6 is a superalloy with high volume fractions of $\gamma^{\prime}\left[\mathrm{Ni}_{3}(\mathrm{Al}, \mathrm{Ti}, \mathrm{Ta})\right]$. Due to the extensive interdendritic segregation of $\gamma^{\prime}$-forming elements the $\gamma^{\prime}$-phase can be formed directly from the interdendritic residual melt, in the form of $\gamma+\gamma^{\prime}$-eutectic. Figure 3 shows the growth process of the eutectic phase. At the onset of the eutectic reaction the $\gamma+\gamma^{\prime}$-islands grow rapidly into the residual melt enriched with $\mathrm{Al}, \mathrm{Ti}$ and $\mathrm{Ta}$, resulting in the fine lamellar structure. The exhaustion of the $\gamma^{\prime}-$ forming elements slows down the growth rate, which leads to the formation of a coarser eutectic structure. In fact, during the eutectic reaction a part of $\gamma$-phase can epitaxially grow at the edge of the $\gamma$-dendrite, due to the enrichment of $\mathrm{Cr}, \mathrm{Co}$ and $\mathrm{Mo}$ in the residual melt. At the end of the solidification the $\gamma^{\prime}$-particles precipitate from the $\gamma$-matrix at the dendrite edge formed just before the eutectic reaction, where more $\mathrm{Al}, \mathrm{Ti}$ and $\mathrm{Ta}$ are contained.

According to Hunt (3) as well as Kurz and Fisher (4), the primary dendrite spacing $\lambda$ is proportional to the product $\mathrm{G}^{-1 / 2} \mathrm{~V}^{-1 / 4}$. The measurements of $\lambda$ are displayed as a function of the product $\mathrm{G}^{-1 / 2} \mathrm{~V}^{-1 / 4}$ in Fig. 4. The data is approximately described by a common straight line, where the increase of $G$ or $v$ lead to a refining of the dendrites. The corresponding relationship between the dendrite size and the process parameters can then be described as $\lambda=1.08 \mathrm{G}^{-1 / 2} \mathrm{v}^{-1 / 4}$, in which the unit of $\lambda$, $\mathrm{G}$ and $\mathrm{v}$ is $\mathrm{mm}, \mathrm{K} / \mathrm{mm}$ and $\mathrm{mm} / \mathrm{min}$, respectively. It must be noted that this simple relationship is only valid for dendritic structure. The cellular size is a complicated function of process parameter (5).

\section{REFERENCES}

[1] WORTMANN J.,WEGE R., HARRIS G., ERICKSON G.L., and SCHWER R.E., "Low Density Single Crystal Superalloy CMSX-6", 7th World Conference on Investment Casing, Munich, (1988).

[2] TIEN J.K. and GAMBLE R.P., Mater. Sci. Eng. 8 (1971) 152.

[3] HUNT J.D., Solidification and Casting of Metals, Metals Society, Book 192, London (1979) 3.

[4] KURZ W. and FISHER D.J., Acta Metall. 29 (1981) 11.

[5] MA D., "Solidification Behaviour of Ni-Base Superalloys", VDI-Verlag Gmbh, Düsseldorf, Germany (1990). 
Table 1: Chemical composition of investigated alloy CMSX-6 (wt.\%).

\begin{tabular}{|l|l|l|l|l|l|l|l|l|l|l|}
\hline $\mathrm{Cr}$ & $\mathrm{Co}$ & $\mathrm{Mo}$ & $\mathrm{Ta}$ & $\mathrm{Al}$ & $\mathrm{Ti}$ & $\mathrm{Hf}$ & $\mathrm{C}$ & $\mathrm{N}$ & $\mathrm{O}$ & $\mathrm{Ni}$ \\
\hline 10.0 & 5.0 & 3.0 & 2.0 & 4.8 & 4.7 & 0.01 & 0.02 & $10 \mathrm{ppm}$ & $9 \mathrm{ppm}$ & bal \\
\hline
\end{tabular}

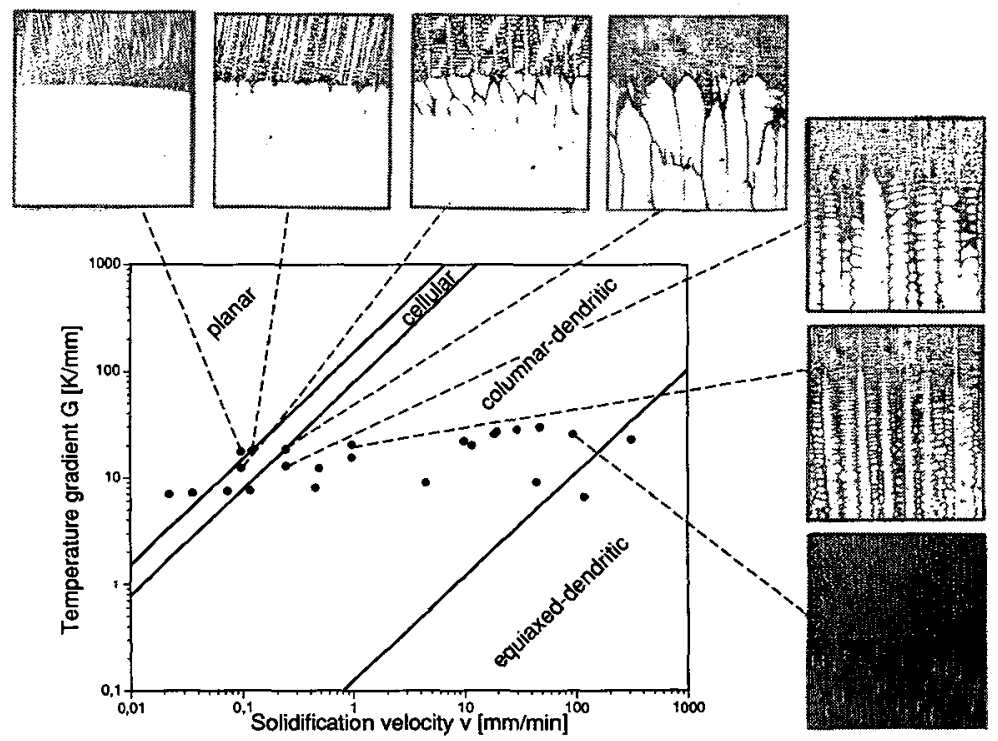

Fig. 1: The solidification diagram for superalloy CMSX-6.

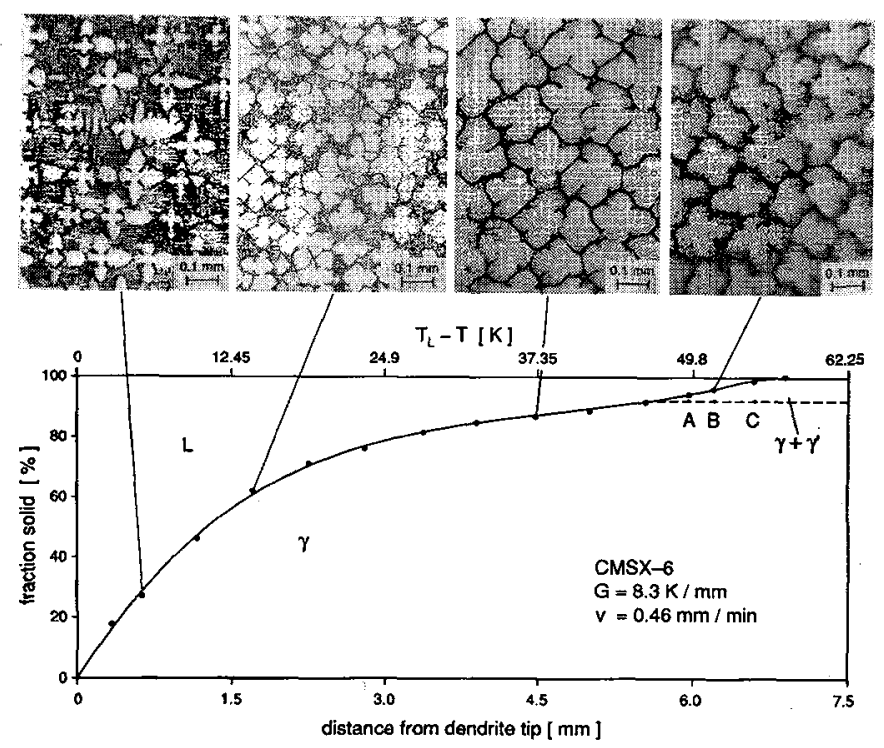

Fig. 2: Evolution of solid fraction in the mushy zone. 


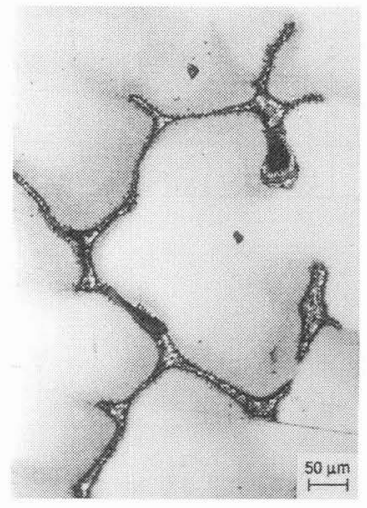

A

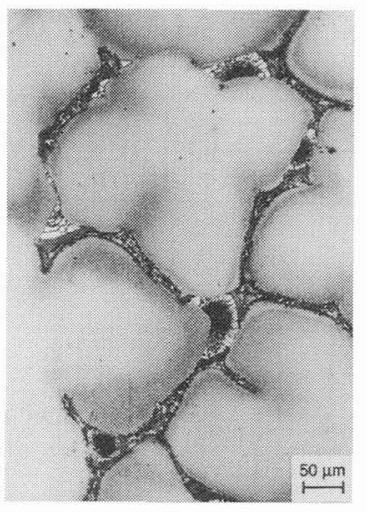

B

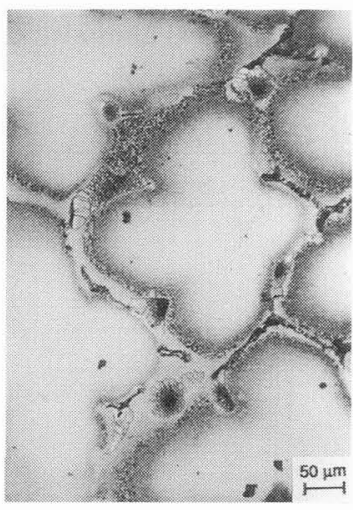

C

Fig. 3: Transverse sections corresponding to the locations A, B and C in Fig. 3 showing the growth process of $\gamma+\gamma^{\prime}$ eutectic from the interdendritic residual melt.

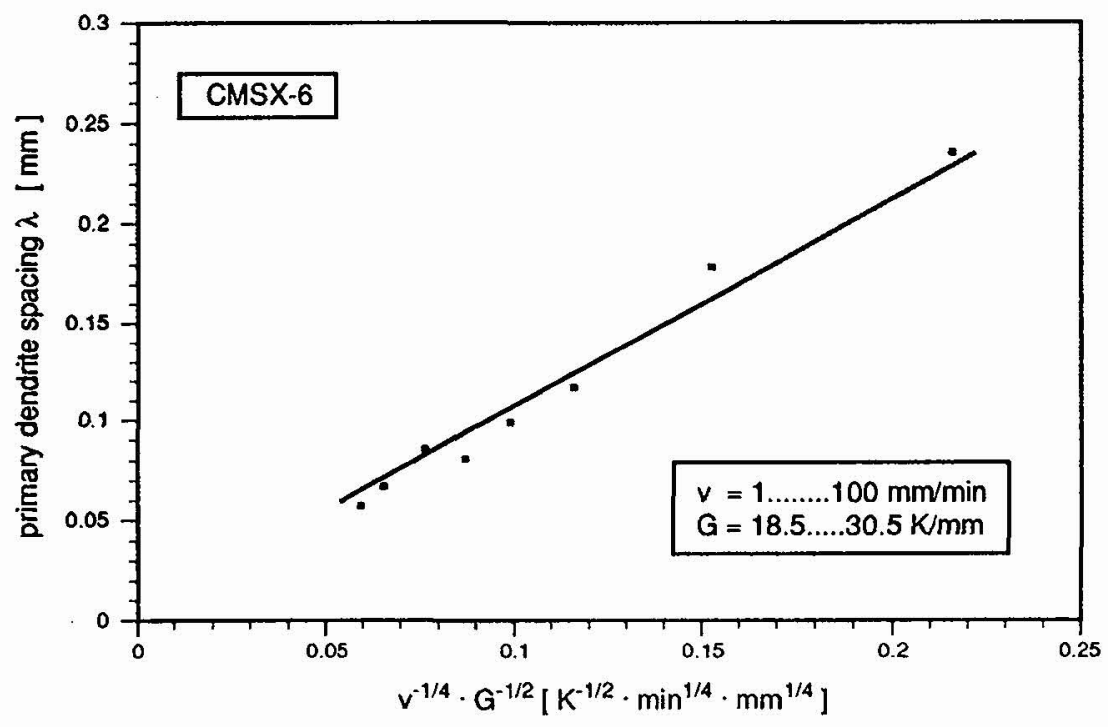

Fig. 4: Measured primary dendrite spacing plotted as function of $\mathrm{G}^{-1 / 2} \mathbf{v}^{-1 / 4}$. 